\title{
SCALING AND MODELING THE CREEP OF Eucalyptus globulus
}

\author{
Duarte Barroso Lopes ${ }^{1, \star}$, João Emílio Matos ${ }^{1}$
}

\begin{abstract}
Eucalyptus, with the commercial name of Blue gum, is a viscoelastic material strongly influenced when under constant load (creep), being this phenomenon - in the context of displacements - exacerbated with transient relative humidity (variations of the water content in the wood material).

The evaluation of bending creep was done in indoor / constant and transient humidity conditions. In the latter, mechano-sorptive effect, the creep bending tests were done for a period of 60 days with cycles of wetting-and-drying. Each cycle has 7 days of duration. Defect free specimens with dimensions of $20 \times 20 \times 400$ $\mathrm{mm}^{3}$ (approximately to the scale 1:10) of Eucalyptus globulus wood species were used.

To fit the creep behaviour and extrapolate results for different periods (1,10 and 50 years) a survey of different numerical models was done. Rational, parabolic and polynomial functions were chosen.

In bending, Blue gum wood species presented a behaviour without a creep limit, therefore labile. Through the models used for extrapolations a significant variability was found for different periods. Values of the main standard of wood design (Eurocode 5) were exceeded. The most consistent mathematical model was the rational model because it is the one that has led to closer and stable results.
\end{abstract}

Keywords: Blue gum, creep limit, eucalypts, mathematical model, mechano-sorption.

\section{INTRODUCTION}

Blue gum Eucalyptus globulus wood specie, is a commercial wood available with low value but plentiful worldwide, particularly in the south of South America (Calvo et al. 2002, Piter et al. 2006, 2007) and North of the Iberian Peninsula (Esteves 2006, Lorenzo et al. 2007, Santos 2009). However, in Portugal its main use is for pulp in the paper industry, it also has a small expression in the building construction of floors and roofs, mostly (DGRF 2010).

In Portugal, two authors have been working with the Blue gum wood species (Esteves 2006, Santos 2000, Santos 2009). The first, through the modification by heat (or thermal), studied physical properties where the equilibrium moisture content EMC reduces and anti-shrink/swelling efficiency ASE improve, both significantly. Durability to brown rot fungus increases significantly. The second studied different physical / mechanical properties and models of behaviours. Concerning to creep, Santos (2009) conducted experiments with specimens with 1:1 scale under uncontrolled conditions. Santos (2009) mentioned that the deformation in creep after 33 days exceeds values suggested by the EC 5 (EN-1995:1-1 2003). At the end, after two years, for Blue gum wood species, the extra-large deformation was the main achieved result.

Blue gum is a dense wood with good characteristics for structural purposes, but it has as well has intrinsic characteristics of the species as setbacks. Its rapid growth and difficult drying and unrolling, due to the

\footnotetext{
${ }^{1}$ Assistant at ISEP School of Engineering of Porto, DEC Department of Civil Engineering, Rua Dr. António Bernardino de Almeida, Porto, Portugal.

•Corresponding author: dbl@isep.ipp.pt

Received: 18.10.2016 Accepted: 13.11.2018
} 
spiral and interlocked grain can manifest itself in interstitial tensions - warping, excessive deformation and distortion (Villegas and Rivera 2002).

Table 1 presents two numerical models (parabolic and polynomial) frequently used in the literature to translate the creep phenomenon in bending (Bodig and Jayne 1982, Epmeier 2006, Santos 2009, Carvalho 2015). Additionally, the rational model was introduced. The choice of a new function (the rational model) was due by the following motives: According to Baker and Graves-Morris (1996), it is well known that the rational functions computed from Taylor series coefficients (i.e. Padé approximants) have good extrapolation properties. Padé approximants, computed in least-square sense, will inherit the good extrapolation properties of the classic ones. On the other hand, the behaviour of extrapolation properties of parabolic and polynomial models is very sensible to small perturbations on coefficients, while the rational model is more stable.

These models (Table 1) are computed in order to be the best fit in least-square sense. To solve these three nonlinear least-square problems, the lsqcurvefit function of the optimization toolbox of MatLab ${ }^{\circledR}$ software was used.

Table 1: Equation 1, Equation 2 and Equation 3 of numerical models.

\begin{tabular}{|r|l|l|}
\hline Model & \multicolumn{1}{|c|}{ Equation } & \multicolumn{1}{|c|}{} \\
\hline Rational - & $\varepsilon(t)=\left(\beta_{0} * t+\beta_{1}\right) /\left(t+\beta_{2}\right)$ & $(1)$ \\
\hline Parabolic - & $\varepsilon(t)=\beta_{0}+\beta_{1} * t^{\beta 2}$ & $(2)$ \\
\hline Polynomial - & $\varepsilon(t)=\beta_{0}+\beta_{1} * t^{\beta 2}+\beta_{3} * t^{\beta 4}$ & $(3)$ \\
\hline
\end{tabular}

To predict a long-term deflection from the initial elastic deflection, a creep factor is recommended (ENV -1156 1999), Equation 4. The creep factor $k_{c}$ is the ratio of the increase deflection with time related to the initial elastic deflection, alternatively defined as ratio of the increase deflection in creep to the instantaneous deflection. The Equation 4 can be rewritten as Equation 5. The term $\varepsilon / \varepsilon_{\text {inst }}=\varphi_{t}$ is the relative creep, i.e., the creep deflection divided by elastic deflection, according to Hoffmeyer (1990) and Mårtensson (2003).

$$
\begin{aligned}
& e=e_{i n s t}\left(1+k_{c}\right) \\
& k_{c}=\frac{\varepsilon-\varepsilon_{\text {inst }}}{\varepsilon_{\text {inst }}}=\frac{\varepsilon}{\varepsilon_{\text {inst }}}-1=\phi_{t}-1
\end{aligned}
$$

The prediction and limitation of deformations in service limit state SLS of the wood structures design can be referred as the creep factor $k_{\text {def }}$ according to Equation 6 . When the final deflection $u_{\text {fin }}$ of a structural member has to be calculated, $\mathrm{k}_{\text {def }}$ is the deformation factor for quasi-permanent actions (10 years or more), according to Equation 5 (ENV-1995:1-1 2003).

$$
u_{\text {fin }}=u_{\text {inst }}\left(1+k_{\text {def }}\right)
$$

Where $u_{\text {inst }}$ is the initial deflection (instantaneous, according to material resistance theory obtained experimentally at 60 seconds) and $k_{\text {def }}$ can assume values up to 2,0 for different durations of load and service classes. The deformation factor $k_{d e f}^{d e f}$ takes into account the combined effect of the load and transient moisture content $\mathrm{MC}$ in the structure.

Parameters which can influence the creep deflection are the level of applied stress, temperature, loading time, the moisture content MC and its variation (Lopes 2013, Fridley et al. 1992, Norimoto et al. 1992, Bengtsson and Kliger 2003, Lagana et al. 2008). However, the most important for the mechano-sorptive effect MSE in structures of wood can be defined by the combined effect of the main factors (loading time and variation of $\mathrm{MC}$ ), which is the fastest (just a couple of weeks of duration) and detrimental way to conduct 
creep experiments at laboratory (Mårtensson 2003). The deflection from the MSE is largely time-independent for pine wood species, Maritime pine (Lopes 2013) and Scot pine (Epmeier et al. 2004). The creep behaviour depends on the applied stress, amount of moisture change and parameters of previous hydro-mechanical loading history (Hauska and Bucar 1996). The test duration has less influence on the MSE part of the deformation than the moistening change (Navi et al. 2002).

This work presents experimental creep results and its extrapolations for Blue gum wood species in bending under steady (indoor) and transient (mechano-sorptive effect MSE) conditions of humidity with different creep models.

\section{MATERIALS AND METHODS}

\section{Material and experimental Set-up}

The standard creep tests were made at three and four points bending (3PB and 4PB) with $1 \times 160 \mathrm{~mm}\left(\mathrm{~L}_{3}\right)$ and $3 \times 160 \mathrm{~mm}$ of span $\left(\mathrm{L}_{1}=100 \mathrm{~mm}, \mathrm{c}=10 \mathrm{~mm}\right)$, in Figure 1(a) and Figure (c) respectively. Both tests were made under constant load according to EN-408 2003 to ensure a stress level SL of $12 \mathrm{MPa}$ (app., with $2 \mathrm{P}=8 \mathrm{~kg}$ ) over 60 days (app.).

The bending deflection was recorded with a specific schedule. According to Figure 1, the deflection was measured from the top surface of the specimens at mid-span, with $160 \mathrm{~mm}$ span, using linear variable differential transducer LVDT gauges. Figure 1(a) shows the test setup for indoor conditions in three point bending 3PB. Figure 1(c) shows the test setup for the mechano-sorptive conditions in four point bending 4PB where the deflection was recorded in the constant moment area along the neutral axis (dash-dotted line) to avoid the effect of swelling and shrinkage of wood movements. Figure (1b) and Figure (1d) shows the cross section where the annual growth rings were cut parallel to their faces, they are stated by inner-vertical grey lines and, they were placed perpendicularly to the supports. According to the loading arrangement in Figure 1(a) and Figure (1c), specimens were loaded on the radial surface in $4 \mathrm{~mm}$ width of the steel-ring of each weight. Care was taken to minimize the impact loading caused by weight application. The loads were gently applied for 20 seconds (app.).

Data taker DT 515 series 3 (with 9 Digital Channels with $0,3 \mathrm{hz}$ of acquisition dates) coupling with 8 LVDT's (type DCTH400/256 ser.111048) with $0,001 \mathrm{~mm}$ precision and a thermo-hygrometer (CPC 1/4-TH nr. 67226) fed with \pm 24 tension volts were used over a period of 1400 hours. LVDTs gauges measured the curvature between the load supports. Data of temperature, RH and displacements from LVDTs were recorded with a PC-based data logging procedure automatically at $5 \mathrm{~s}$ of intervals (for the first 4 hours) at the beginning of each test/cycle, for the setup in the Figure 1(a) and Figure (1c). Then, every 30 minutes until the end of the test/cycle was reached. In the case of the mechano-sorptive effect (Figure 1c), the same procedure was repeated every week.

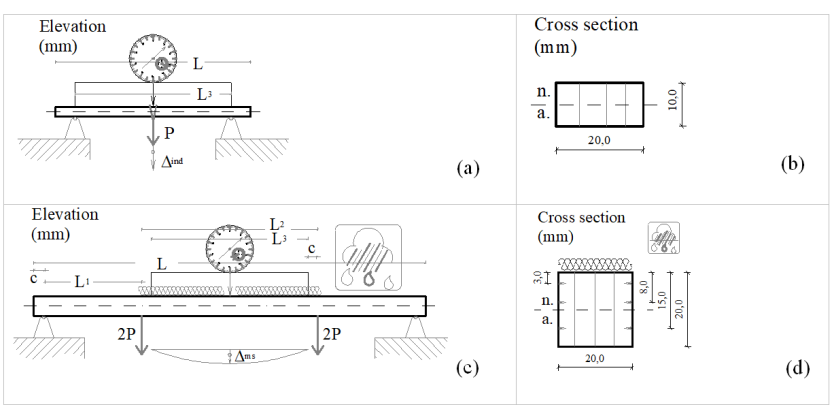

Figure 1: Setup of the load arrangement for creep tests in bending (a) Indoor climate with deflection $\Delta_{\text {ind }}=\left(\mathrm{P} \mathrm{L}_{3}{ }^{3}\right) /\left(4 \mathrm{E} \mathrm{b} \mathrm{h}^{3}\right)$;(b) Specimens cross section with 20x10x200 $\mathrm{mm}^{3} \mathrm{RTL}$; (c) Moistening for mechano-sorptive climate and load arrangement with deflection $\Delta_{\mathrm{ms}}=\left(15 \mathrm{P} \mathrm{L}_{3}{ }^{3}\right) /\left(16 \mathrm{E} \mathrm{b} \mathrm{h}^{3}\right)$; (d) Specimens with $20 \times 20 \times 400 \mathrm{~mm}^{3} \mathrm{RTL}$ and points of local measurements of moisture content in the cross section at different depths from the radial wetted surface $(3,8$ and $15 \mathrm{~mm})$. 
The creep behaviour test under indoor conditions, was done with relative humidity $\mathrm{RH}$ constant at $65 \%$, i.e. the environment had no transient MC. Without any moistening and the environment RH kept constant, samples used in Figure 1(a) setup, showed the EMC constant, see Table 2 at item 3.1.

Both setups with different environmental conditions, indoors and under the mechano-sorptive effect, are the most used environment conditions in scientific studies of creep (Epmeier 2006, Epmeier et al. 2007, Santos 2009). Both setups intend to present the creep behaviour of Blue gum (Eucalyptus globulus Labill) wood specimens. With 3PB, in Figure 1(a) for indoor conditions, showed large deflection and 4PB, in Figure 1(c) for mechano-sorptive effect, it is more stable and recommended (ENV-1156 1999, EN NP-408 2003).

\section{Mechano-sorptive effect, MSE}

We call it MSE when the results of creep are obtained under constant load but varying the MC of the wood material, simultaneously. The MSE is the way to accelerate the deformation in a shorter period of time. The moistening was done in the upper side of the wood specimen in the compression zone of $180 \mathrm{~mm}$ extension (between load shoes, $2 \mathrm{P}$ of $16 \mathrm{~kg}$ approximately $\mathrm{P} \cong 80 \mathrm{~N}$ ) and whose ends were dipped in a container to adsorb distilled water by capillarity (over 5 hours per cycle each week), Figure 1(c) and Figure (1d). A strip of filter paper with $20 \mathrm{~mm}$ width over the length development of the specimen, plus $15 \mathrm{~mm}$ on each end side was dipped in two containers with $20 \mathrm{mll}$ approximately. The moistening processes were initiated after seven days/first week of loading and repeated every week until 7 cycles were reached (63 days / 1500 hours, approximately).

The length of the cycle was defined with a preliminary evaluation (Lopes 2013). During the cycle of wetting and drying and under similar conditions, the MC development under the same moistening procedure MSE was evaluated for unloaded specimens. Afterwards, the MC was measured with a Protimeter Moisture Measurement System (PROTIMETER 2005).

Protimeter based its measurements in the electrical method. Two pins were pressed against the tangential surface of wood specimens, with few millimetres $(2-3 \mathrm{~mm})$ of penetration. After few seconds, MC was obtained in 3 depths, according to Figure 1(d). The average of readings at both sides of the cross section and at three depth was taken and presented in Figure 2.

This procedure of MSE was done only with samples at four points bending, Figure 1(c) and Figure (1d). These environmental conditions are similar to Mediterranean climate in Southern Europe with moistening variation by a downpour and low or medium RH on the remaining days of the week.

\section{RESULTS}

The load was selected in such way to ensure the bending stresses of $10 \%$ of the mean modulus of rupture MOR determined with wood specimens conditioned at EMC, with $65 \%$ of RH. Small samples 20x10x200mm were tested in three points bending configuration 3PB (according to DIN-52186 1978) using a SHIMADZU AG-X10KN machine. The average of $115 \mathrm{MPa}$ of MOR was lower than the values presented by Esteves (2006) and Carvalho (1997). These authors showed values of 131 to $167 \mathrm{MPa}$ for the same species of Eucalyptus. For both setups, the load $\mathrm{P}$ was done with a concrete cube with $8 \mathrm{~kg}$ that lead a medium stress level SL of 10 and $12 \mathrm{MPa}$, respectively for setup in Figure 1(a) and Figure 1(c).

For fitting curves and forecasting, data / results for different periods (1, 10 and 50 years), the MatLab ${ }^{\circledR}$ software was used. For unconstrained models, the Gauss-Newton method was used as default algorithm, to find the minimum of a function that is a sum of squares of non-linear function.

Creep results are shown using a box plot characterized by the standard deviation through a rectangle, average (-), median (x), upper and low whisker with 5 and 95 percentile, see Figure 4 i.e.. The statistical analysis was done using the ORIGIN ${ }^{\circledR} 8.5$ software and tested with univariable analysis, followed by a t-test with a $95 \%$ confidence interval. For comparative purposes, to verify whether a result was significantly different or not, the level for significance was set at $\mathrm{p}<0,05$. 


\section{Moisture content MC}

Flawless specimens of Blue gum wood species (Eucalyptus globulus Labill.) from pure heartwood part of the stem were prepared with a mean density of $920 \mathrm{kgm}^{-3}$. Two sets of six specimens were conditioned at $21^{\circ} \mathrm{C}$ of temperature $\mathrm{T}$ and $65 \%$ relative humidity $\mathrm{RH}$ for at least eight weeks to reach the equilibrium moisture content EMC. After the conditioning and at the beginning of the experiments, the EMC was 8\% on average for both sets of specimens. The MC was determined by the gravimetric method. All specimens were dried and weighted before conditioning and were also weighted after conditioning. The means and standard deviation of all specimens were shown in Table 2. In the left part of Table 2 are the specimens of the experiment with 3PB, in Figure 1(a) wheras on the right part are the specimens of experiment with 4PB, in Figure $1(\mathrm{c})$.

Table 2: Dimensions, density and moisture contents of Blue gum specimens used in both setups at Figure 1(a) and Figure (1c).

\begin{tabular}{|c|l|l|l|l|l|l|l|l|l|l|l|l|}
\hline & Weight & $\mathbf{R}(\mathbf{m m})$ & $\mathbf{T}(\mathbf{m m})$ & $\mathbf{L}(\mathbf{m m})$ & Density & MC & Weight & $\mathbf{R}(\mathbf{m m})$ & $\mathbf{T}(\mathbf{m m})$ & $\mathbf{L}(\mathbf{m m})$ & Density & MC \\
\hline Samples & (grams) & radial & tang. & long. & $\left.\mathbf{( k g m}^{-3}\right)$ & $\mathbf{( \% )}$ & $\mathbf{( g r a m s )}$ & radial & tang. & long. & $\mathbf{( k g m}^{-3}$ ) & $\mathbf{( \% )}^{\mathbf{\%}}$ \\
\hline 1 & 35,7 & 20,2 & 10,1 & 200 & 871 & 9,0 & 63,3 & 20,1 & 20,0 & 400 & 930 & 8,6 \\
\hline 2 & 40,6 & 20,4 & 10,3 & 200 & 972 & 7,8 & 68,4 & 20,3 & 20,2 & 400 & 940 & 7,9 \\
\hline 3 & 37,2 & 20,3 & 10,4 & 200 & 880 & 8,6 & 64,3 & 20,4 & 20,3 & 400 & 904 & 8,4 \\
\hline 4 & 36,0 & 20,2 & 10,1 & 200 & 878 & 8,9 & 62,4 & 20,4 & 20,0 & 400 & 906 & 8,7 \\
\hline 5 & 39,1 & 20,3 & 10,2 & 200 & 941 & 8,1 & 66,7 & 20,1 & 20,1 & 400 & 940 & 8,1 \\
\hline 6 & 41,1 & 20,3 & 10,3 & 200 & 979 & 7,7 & 69,7 & 20,4 & 20,2 & 400 & 941 & 7,7 \\
\hline Medium & $\mathbf{3 8 , 3}$ & $\mathbf{2 0 , 3}$ & $\mathbf{1 0 , 2}$ & $\mathbf{2 0 0}$ & $\mathbf{9 2 0 , 2}$ & $\mathbf{8 , 4}$ & $\mathbf{6 5 , 8}$ & $\mathbf{2 0 , 3}$ & $\mathbf{2 0 , 1}$ & $\mathbf{4 0 0}$ & $\mathbf{9 2 6 , 9}$ & $\mathbf{8 , 2}$ \\
\hline STV & 2,3 & 0,1 & 0,1 & 0,0 & 49,9 & 0,6 & 2,9 & 0,1 & 0,1 & 0,0 & 17,4 & 0,4 \\
\hline
\end{tabular}

In the MSE experiments with samples in Figure 1(c) - with great dimensions (20x20x400 mm), to check the $\mathrm{MC}$ distributions in the cross section of the Blue gum wood specimens, Figure 1(d), a preliminary experiment was done to clarify some doubts:

The first one, it should clarify whether the moistening process is suitable to produce a MC changing.

The second one, it was an attempt to establish the length of the cycle for the duration creep-test, in a way to reach the wood MC stabilization after the wet-and-drying cycle.

The third and last one, checked the MC above and below the neutral axis (n.a.). In other words, which level of MC is reached with this asymmetric moistening procedure, Figure 1(a) and Figure 1(b).

The $\mathrm{MC}$ in the Blue gum cross section (at different depths $\star 3 \mathrm{~mm}$, it $8 \mathrm{~mm}$ and $* 15 \mathrm{~mm}$, Figure 1(d) was reached with Protimeter MMS moisture-meter. Figure 2 shows the means of the MC distributions at different depths of the cross section during the upper surface moistening us Figure 1d.

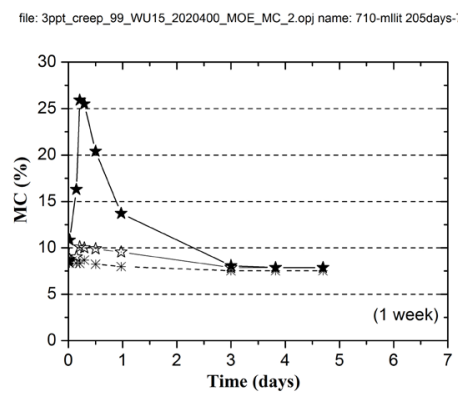

Figure 2: Profile of the moisture content MC (\%) in the cross section of Blue gum specimens with moistening process on the top radial-upper surface at depths:

$\star 3 \mathrm{~mm}$, is $8 \mathrm{~mm}$ and $* 15 \mathrm{~mm}$, (also Figure 1d). 
Below the neutral axis n.a., the MC was unaffected by the moistening. However, above n.a. the MC reached was similar to the equilibrium moisture content EMC found in the wetted stabilized conditions, at RH of 87\% in Lopes (2013) and Esteves (2006) with the same wood species. Only one part of the cross section (up the n.a. to the side of the moistening) has changed the MC. This effect produced the MSE only in one part of the bending beam - compression zone.

\section{Creep behaviour}

The surrounding environment is extremely important for the deformation behaviour in creep. In an indoor scenario, the environment conditions are less severe than MSE conditions and to get extrapolated results at 63 days, 10 and 50 years, numeric models of Table 1 were used and results are presented at item 3.3.

Figure 3 shows the compliance curves of relative creep in percentage over a period of 63 days, i.e. 1500 hours. Each dark line means one tested specimen. The application of the mathematical model at one wood sample leads to the dash-dot overloaded line. Two developments of the relative creep curves, in both structural schemes, were found. The behaviour of the samples in indoor conditions has constant RH and MC, setup with 3PB in Figure 1(a) and results were showed in Figure 3(a). On the other hand, the behaviour under the MSE (Figure 1(b)), with transient MC were showed in Figure 3(b).

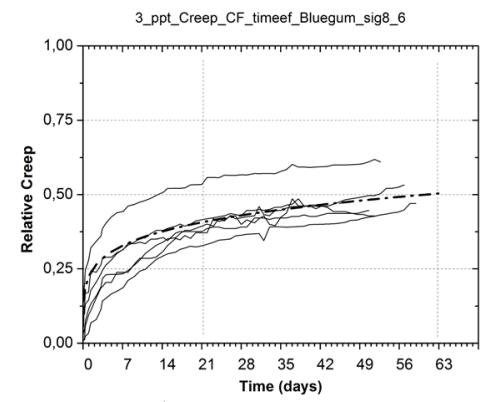

(a)

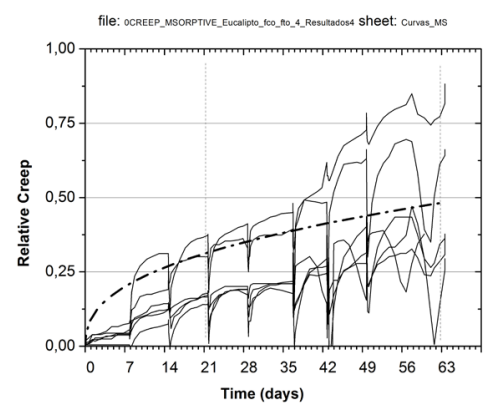

(b)

Figure 3: Relative creep under SL of $12 \mathrm{Nmm}^{-2}$ for Blue gum wood species, (a) 3PB - Indoor conditions, $65 \%$ of RH and (b) $4 \mathrm{~PB}$ - Mechano-sorptive effect, transient MC.

For both structural setups, with 3PB in Figure 1(a) and with 4PB in Figure 1(c), two types of curves were found. For 3PB in Figure 3(a), a rapid progress during the first 2 days (48 hours), followed by a stabilization at the end of 3 weeks ( 21 days) was showed for all specimens. Small displacements occurred due to the constant $\mathrm{RH}$ of the environment.

Under the mechano-sorptive effect with transient conditions, with 4PB in Figure 1(c) and results in Figure 3 (b), a rapid evolution during the wetting-and-drying course without a clear stabilization was presented even at the end of seven cycles, between 49 and 63 days in Figure 3(b). The upsets in the relative creep curve appearing due to the wetting over 5 hours per cycle each week. The first linear descendent, is due to the swelling of the wood - where the value of the relative creep " $\varphi_{t}$ " decreases, followed by softening of the material where the deformation increases and stabilizes on the fourth day of each cycle.

Both spans, in 3PB in Figure 1(a) and in $4 \mathrm{~PB}$ in Figure 1(c), are similar $\left(\mathrm{L}_{3}=160 \mathrm{~mm}\right)$ but deflection should not be compared. In the first 3PB, the deflection is total and result from bending and shear, whilst for 4PB it is the differential deflection at mid span obtained under pure bending, i.e. without shear contribution. However, with the same material, same width and half height of test pieces, and similar load, under linear behaviour according to formulas presented in Figure 1a) and c), the deflection in 3PB is double compared to the deflection in $4 \mathrm{~PB}$.

After the first week ( 7 days) and in the development of the remaining 8 weeks, in the same period of time (63 days), similar deflections were obtained for both setups in Figure 1(a) and Figure (1c). The slope of the compliance creep curves describes the creep limit. For 3PB in Figure 1(a) has great linear deformation and 
lower creep limit at Figure 3(a) than 4PB at Figure 3(b). In Figure 3(b) the deflection of relative creep was obtained with lower linear deformation and higher creep limit due to the mechano-sortive effect that accelerated the deflection. This result lead to a similar value of relative creep for both setups (Figure 1(a) and Figure 1(c)).

\section{Creep results, at indoor conditions}

The deflection in the material under creep can be divided into 4 parts: linear or elastic, viscoelastic, viscoplastic and the unstable deformation until the rupture. The last one occurs just in case of collapse. The instantaneous deflection is obtained according to the material resistance or linear behaviour, is followed by the primary creep deflection that occurred after the first hours and days of the loading - viscoelastic part. The stable or the secondary creep deflection occurred after the first week - viscoplastic part.

For three models of Table 1, fitting and extrapolation for 63 days, 10 and 50 years was done. These extrapolation periods were selected because, the first one was the test duration. The second and third, 10 and 50 years, to simulate interim and normal structures - average lifespan of a building without the need of any major maintenance - according to EC 0 (EN-1990 2009).

For relative creep curve, fitted and extrapolated, at 63 days, with three creep models (Table 1), results were shown in Figure 4. Figure 4(a) shows fitted results at the same time of extrapolation, 63 days, however in the case of " 21 " only 21 days of data (300 hours, app.) had been used. All coefficients " $\beta$ " constituent of all mathematical models were initialized at " 0 ".

Comparatively for the same time of the extrapolation - 63 days, the durability of the test, using data of 21 or 63 days, with the parabolic and polynomial models, is important. Parabolic and polynomial models have significant different results, if the test 21 or 63 days long. In the same context of comparison at 63 days extrapolation, rational model, regardless the time taken for extrapolating (63 days, 10 and 50 years, respectively in Figure 4(a), Figure 4(b) and Figure 4(c) ), all extrapolated results were not significantly different if both periods of duration, 21 or 63 days, were used.

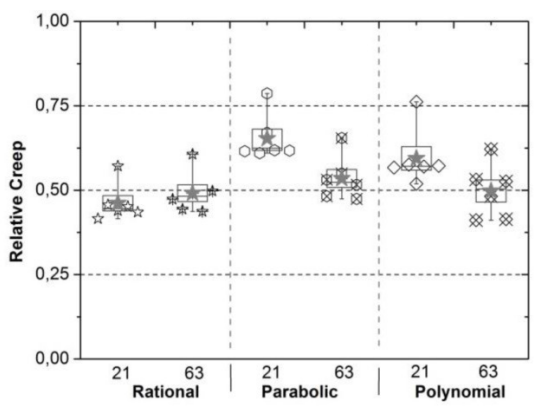

(a)

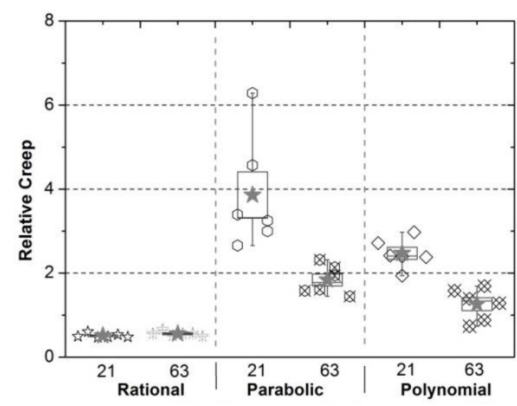

(b)

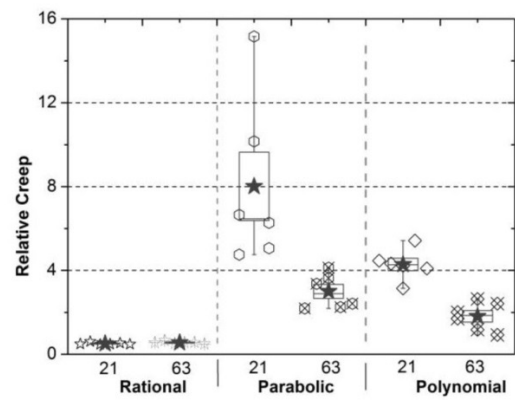

(c)

Figure 4: Results extrapolated at 63 days and fitted with three creep models (Table 1) to the relative creep deformation curve of the Eucalyptus specimens in indoor conditions with data from " 21 " and " 63 " days; (a) at 63 days, (b) at 10 years and (c) at 50 years. 
At 50 years of extrapolation only through the rational model could be achieved relative creep on the same magnitude of EC 5 suggestion $-\mathrm{k}_{\mathrm{def}}=0,60$, Figure 4(c), despite the dimensions of data used ( 21 or 63 days). In other models, parabolic and polynomial, values obtained by extrapolation exceeded the EC 5 suggestion. In the dimensions of data of 63 days, i.e. the duration of 63 days of test, for which the latter models are performing better, the extrapolation is about 300\% higher than EC 5 suggestion (on average). In the duration of 21 days of test, i.e. the extrapolations were done with the dimensions of data of 21 days, the parabolic model is the one which has significantly higher values and with higher deviation, in a short durability. Even for small specimens at 1:10 scale, which are well known to deform significantly more than specimens with 1:1 scale (Piter et al. 2006), the rational model presented results similar with magnitude as EC 5 suggestion, comparing extrapolation done for 50 years.

For indoor conditions, we can conclude that the rational model is the one that behaves better because it is not influenced by the considered data of 21 or 63 days and it turned out not significantly different extrapolation results (Figure 4(a)). In these experiments, in indoor conditions, significantly lower deformation was obtained when results are compared to MSE presented in next Figure 5 and Figure 6 due to the lower creep limit presented in the course of the tests carried out.

\section{Creep results, mechano-sorptive effect}

For the structural setup, with 4PB in Figure 1(c), the results of creep behaviour under the mechano-sorptive effect in Figure 3(b), similar procedure of extrapolation was done.

Models in Table 1, polynomial and parabolic, are sensitive to the initialization of " $\beta$ " coefficients. In the following Figure 5(a), Figure 5(b) and Figure 5(c), respectively with circles $(\mathrm{O})$ and $(\mathrm{x})$, are shown extrapolated results, with initializing constituent constants of polynomial and parabolic models respectively with null and one, 0 and 1 (see " $\beta$ " coefficients of each model in Table 1). Nonetheless rational model doesn't depend on any initialization, extrapolation values are represented by five-pointed star ( $\lambda$ ), only in one single column $(\theta+)$.

Final fitted results are not significantly different for the 63 days duration of the experiment. However, significantly different results were obtained for the polynomial model and for a period of extrapolation of 10 or 50 years, depending on the start-up of $\beta$ constant at 0 or 1 . The initialization value " 1 " leads the convergence to negative results. In this case, this result has no physical meaning. As they were not true, negative results were not presented at Figure 5(a), Figure 5(b) and Figure 5(c). For initialization the coefficients $\beta$ at " 0 ", positive and higher values are found for 63 days, 10 and 50 years extrapolation.

Final fitted results for the parabolic model happen in the other way round. For three duration times ( $63 \mathrm{~d}$, $10 \mathrm{y}$ and 50 years) the coefficients initialization $\beta$ at " 0 " or " 1 " did not show significant different values. In other words, as a rational model, parabolic model is stable, not being sensitive to the initializing constants that constitute the model, even for long duration of the extrapolation, 50 years.

Since the standard deviation was similar whichever the initialization " 0 " or " 1 ", the parabolic model can be presented as a weak model for this procedure of extrapolation with the wood of Eucalyptus, showing bad extrapolation properties. The polynomial model was not robust due to the sensitivity of " $\beta$ " initialization. The rational model does not have the above disadvantages, of the compared models - polynomial and parabolic, i.e. it is stable (it has always finite limit, which is an extra guarantee). 

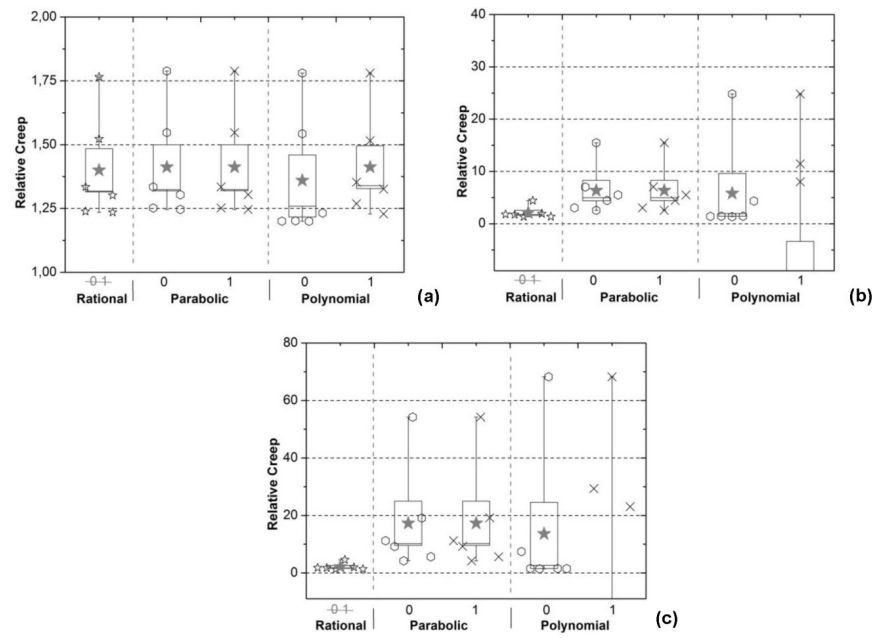

Figure 5: Results extrapolated with three creep models (Table 1) to the relative creep deformation curve of the Eucalyptus specimens under mechano-sorptive effect; (a) at 63 days, (b) 10 years and (c) 50 years.

The standard deviation and no convergence - creep limit for Eucalyptus wood species with these three extrapolation models (Table 1), the duration test was analysed too, see Figure 6 . The experiments were conducted in 63 days data ( 7 cycles of moistening duration) to study the MSE. For 21 days ( 3 cycles) similar extrapolation was done with coefficients " $\beta$ " initialized at " 0 " for both periods to be compared.

The following results of relative creep under MSE, with 4PB setup in Figure 1(c) and creep behaviour in Figure 3(b), are shown in Figure 6. For three mathematical models, Rational, Parabolic and Polynomial, see Table 1, stars with points, circles and squares / diamonds ( $\lambda \vec{\gamma}, \mathrm{O}$ and $\diamond)$ were used to show extrapolated results. In the following figures, Figure 6(a), Figure 6(b) and Figure 6(c) different times of extrapolation (63 days, 10 and 50 years) were done. For both extrapolation, when data values were used - 63 days ( 7 cycles) and 21 days ( 3 cycles, i.e. 21 days of duration test) - the same characters ( $\lambda, \mathrm{O}$ and $\diamond$ ) with cross on or not were used to show results with 63 and 21 days of data, respectively.

With the reduced test duration of 21 days ( 3 cycles of wetting and drying), the adjusted results and extrapolated to 63 days duration are significantly different $(\mathrm{p}>0,05)$ between the three models used (Table 1). Significant differences between all three models are also found for 10 and even 50 years extrapolated results, see Figure 6(b) and Figure 6(c).

In Figure 6(a), for the 21 days test duration ( 3 cycles), all models have values with significantly larger standard deviations. Between models, results are significantly different, with polynomial model showing lower values, the rational model showing less deviations and parabolic model showing higher values and higher deviations. The tendency was continued, and even exaggerated, when extrapolations for 10 years - in Figure 6(b) and 50 years - in Figure 6(c) were analysed.

Results extrapolated with data of 63 days (in columns of "63" in the Figure 6 with characters ( $\lambda$, $\mathrm{O}$ and $\diamond)$ with cross on) are the same for columns " 0 " in the Figure 5. For all mathematical models, results were higher and significantly higher standard deviation was found when fewer data are used for extrapolation (21 days). A creep test with maximum duration will be desired, in this case, 7 cycles would be appropriate. Even for maximum data of 63 days $(7$ cycles), parabolic and polynomial are weak models for the procedure of extrapolation of this wood species, Eucalyptus, showing bad extrapolation properties. The rational model does not have the above disadvantages when compared to models - polynomial and parabolic, i.e. The rational model is stable and even showed results within the range suggested in the EC 5. EN-1995 (2003) suggest a creep coefficient of 2 for the service class 3 . This means, that the linear displacement should be $300 \%$ higher, at the end of 50 years of the building duration.

All nonlinear equations of mathematical models give residues in their fitting process. Residues appearing from the difference between the value of the exact curve of the mathematical model and discrete data value 
obtained at any time of the reading of the creep behaviour, positive or negative values can be assumed. See the difference between the continuous line and the dash-dot overloaded line in Figure 3(b). The residues found are higher for a longer period of duration test, i.e. for 63-day time of data used to extrapolation. As expected, more data to fit, the higher residue of the fitting. In other words, for 63-day time, residues are higher than for a duration of 21 days of testing period. By this token, it does not present any values of residue or have been made any comparison. In equal duration of the test, the residue is independent of the initializations of constant constituents of models " $\beta$ " in the Table 1, i.e. " 0 " or " 1 " didn't affect the results.
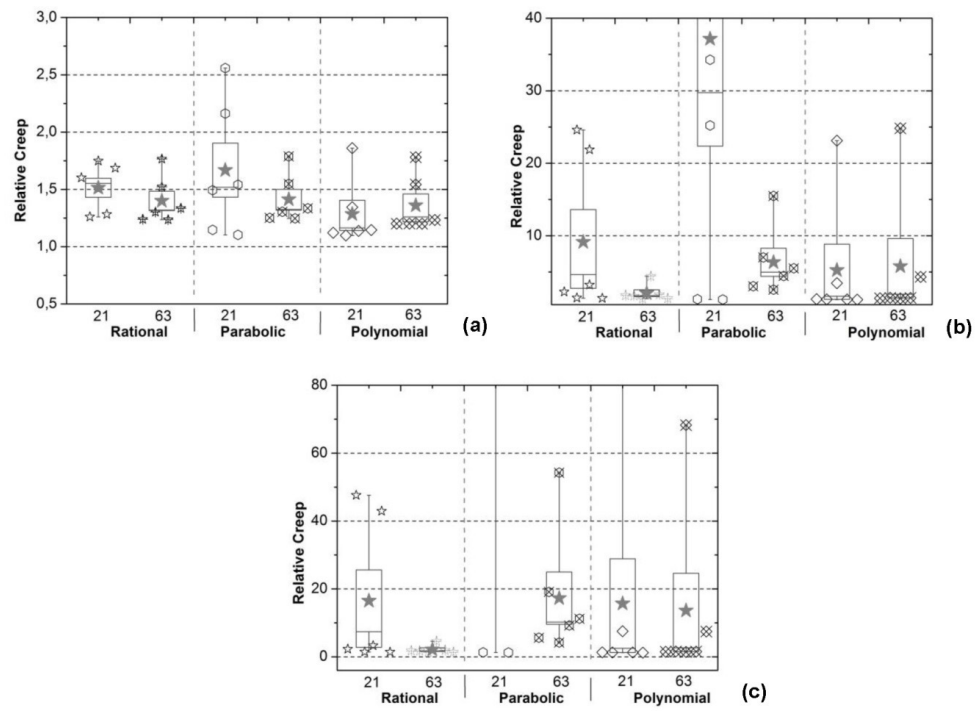

Figure 6: Results extrapolated with three creep models (Table 1) to the relative creep deformation curve of the Eucalyptus specimens under mechano-sorptive effect; (a) at 63 days, (b) 10 years and (c) 50 years. Mathematical models: Rational - $\downarrow$; Parabolic - O and Polynomial - $\diamond$, with 21 days of data and the same characters with cross on with 63 days of data used in the extrapolation.

Calvo et al. (2002) studied the creep behaviour in 3 points bending test with Eucalyptus grandis wood specimens (20x30x570 mm RTL, scale 1:10 app.) for long term duration (400 days app. 58 weeks) under no controlled environment (service class 2 according to EC 5). Similar increasing of relative creep (app. 0,50) after 55 days and several cycles of wetting and drying were found, see Figure 4(a), rational model e.g.. As the previous authors, Piter et al. (2007) worked with the same wood and studied the influence of mechano-sorptive effect as well as the existence of marrow in the wood species of E. grandis. Despite the different scale of the specimens used (scale 1:1 app. and 50x100x3000 mm, RTL dimensions, and the service class 3), they showed similar results to Calvo et al. (2002). The presence of marrow accelerates the deformation in the first age. The difference between both studies was the service class and the scale of specimens. Large dimension specimens creep less, however the mechano-sorptive effect (class 3 ) was more adverse than class 1 or indoor conditions.

Okimoto (2001) showed the behaviour of the Eucalyptus citriodora under simple compression creep test after 60 days with 7 of relative creep value. The wood compression behaviour is the main contributor to the creep behaviour (in bending, our experiment case) was showed that with this setup the mechano-sorptive effect can be studied.

\section{CONCLUSIONS}

The creep behaviour of Blue gum wood species under two environmental conditions, service class 1 and 3 - respectively, indoor and mechano-sorptive effect) with reduced scale 1:10 specimens (in lab conditions) was presented.

Although different service conditions were used from a real case (scale 1:1), different creep models (par- 
abolic and polynomial) showed different and higher results than Eurocode EC 5 suggestion $\left(k_{\text {def }}\right)$.

The rational model is the one that presents more consistent results, independently of the test duration (21 or 63 days), constant initialization ( 0 or 1 ) or extrapolation time (63 days, 10 or 50 years).

\section{REFERENCES}

Baker, G.A.; Graves-Morris, P.R. 1996. Padé Approximants. Encyclopedia of Mathematics and its Applications. Cambridge University Press, ISBN 9780521450072, vol. 59.

Bengtsson, C.; Kliger, R. 2003. Bending creep of high-temperature dried spruce timber. Holzforschung 57:95-100.

Bodig, J.; Jayne, B.A. 1982. Mechanics of wood and wood composites. New York, Cincinnati, Toronto, London, Melbourne, Van Nostrand Reinhold Company, p.712. ISBN 0-442-00822-8.

Calvo, C.F.; Cotrina, A.D.; Cuffré, A. G.; Piter, J. C.; Stefani, P. M.; Torrán, E. A. 2002. Creep in small clear specimens of Argentinean Eucalyptus grandis. Maderas-Cienc Tecnol 4(2):124-132.

Carvalho, A. 1997. Madeiras Portuguesas, vol. II. Estrutura anatómica, propriedades, utilizações. Ed. Direç̧ão Geral das Florestas: Lisbon. ISBN 9789728097264, p.415.

Carvalho, S.V.S. 2015. Creep materials (Fluência de materiais). Master Thesis (n. $\left.{ }^{\circ} 1323\right)$. School of Engineering of Oporto. p.112.Available < http://hdl.handle.net/10400.22/8113>(access:13/ 11/ 2018).

Deutsches Institut für Normung. DIN. 1978. Testing of wood; Bending test. DIN 52186. 1978.

Direcção geral de recursos florestais. DGRF. 2010. $5^{\circ}$ Inventário florestal Nacional, <http://www.afn. min-agricultura.pt/portal/ifn/relatorio-final-ifn5-florestat-1> (access: 13/11/2018).

European Committee for Standardization. ENV. 1999. Wood-based panels. Determination of duration of load and creep factors. ENV-1156. 1999. CEN European Committee for Standardization. ISBN 0580321371.

European Committee for Standardization. EN-NP. 2003. Timber structures - Structural timber and glued laminated timber - Determination of some physical and mechanical properties. EN-NP-408. 2003. CEN European Committee for Standardization: Bruxelles.

European Committee for Standardization. EN. 2003. EC 0, Eurocode 0 - Eurocode - Basis of structural design. EN-1990. 2003. CEN European Committee for Standardization: Bruxelles.

European Committee for Standardization. EN. 2003. EC 5, Eurocode 5 - Design of timber structures - Part 1-1: General - Common rules and rules for buildings. EN-1995:1-1. 2003. CEN European Committee for Standardization: Bruxelles.

European Committee for Standardization. EN. 2009. EC 0, Eurocode 0 - Basis of structural design. EN-1990. 2009. CEN European Committee for Standardization: Bruxelles.

Esteves, B.M.M.L. 2006. Melhoramento tecnológico por modificação térmica de madeiras Portuguesas. $\mathrm{PhD}$ Thesis, Universidade Técnica de Lisboa, I.S. Agronomia, Lisboa, Portugal.

Epmeier, H. 2006. Moisture-related properties of modified timber - an experimental study. PhD Thesis, Chalmers Tekniska Högskola, Institutionen för tillämpad mekanik, Goeteborg, Sweden.

Epmeier, H.; Westin, M.; Rapp, A. 2004. Differently modified wood: Comparison of some selected properties. Scandinavian Journal of Forest Research 19(5): 31-37.

Epmeier, H.; Johansson, M.; Kliger, R.; Westin, M. 2007. Bending creep performance of modified timber. Holz Roh Werkst 65: 343-351. 
Fridley, K.J.; Tang, R.C.; Soltis, L.A. 1992. Creep behavior model for structural lumber. Journal of Structural Engineering 118:2261-2276.

Hoffmeyer, P. 1990. Failure of wood as influenced by moisture and duration of load. PhD Thesis, State University of New York, Syracuse, New York.

Hauska, M.; Bucar, B. 1996. Mechano-sorptive creep in adult, juvenile and reaction wood. In: Proceedings of the International COST 508 Wood Mechanics Conference, Stuttgart, Germany.

Lagana R.; Babiak M.; Krakovsky A. 2008. Creep parameters of spruce wood in high temperature environment. Madera-Cienc Tecnol 10(1): 19-24.

Lopes, D.B. 2013. Technological improvement of Portuguese pinewood by chemical modification. $\mathrm{PhD}$ Thesis, Georg-August-Universität Göttingen, Göttingen, Germany, 146p. Available $<$ http://hdl.handle. net/11858/00-1735-0000-0001-BB4B-C > (access: 13/11/2018).

Lorenzo, D.; Troya, M.T.; Prieto, M.J.; Baso, C.; Touza, M. 2007. Study of the natural durability of Spanish Eucalyptus globulus Wood. In Proceedings IRG 38 th Annual Meeting IRG/WP 07-10617 The International Research Group on Wood Protection: Jackson Lake Lodge, Wyoming, USA. 20-24 May.

Mårtensson, A. 2003. Short- and long-term deformations of timber structures. Edited by Thelandersson, S; Larsen, HJ. John Wiley \& Sons Ltd: West Sussex, England. ISBN 0-470-84469-81.

Navi, P.; Pittet, V.; Plummer, C.J.G. 2002. Transient moisture effect on wood creep. Wood Science and Technology 36(6): 447-462.

Norimoto, M.; Gril, J.; Rowell, R.M. 1992. Rheological properties of chemically modified wood: Relationship between dimensional stability and creep stability. Wood Fiber Science 24(1):25-35.

Okimoto, F.S. 2001. Análise da perda de protensão em pontes protendidas de madeira. $\mathrm{PhD}$ Thesis, Escola de Engenharia de São Carlos, Universidade de São Paulo. São Carlos, Brasil. Available $<$ http://www.teses. usp.br/teses/disponiveis/18/18134/tde-10092015-141647/en.php> (access: 13/11/2018).

Piter, J.C.; Calvo, C.F.; Cuffré, A.G.; Rougier, V.C.; Sosa Zitto, M.A.; Torrán, E.A. 2007. Creep in structural-sized beams of Argentinean Eucalyptus grandis. Maderas-Cienc Tecnol 9(2):117-126.

Piter, J.C.; Zerbino, R.L.; BLAß, H.J. 2006. Deflections in beams of Argentinean Eucalyptus grandis under long-term loading. Holz als Roh- und Werkstoff 64(5):351-355.

PROTIMETER. 2005. Instruction manual protimeter moisture measurement system MMS, INS5800A. Available $<$ http://www.ge-mcs.com/download/sensing-manuals/MMS-Instruction.pdf $>$ (access: 5/10/2011).

Santos, J.A. 2000. Mechanical behaviour of Eucalyptus wood modified by heat. Wood Science and Technology 34(1):39-43.

Santos, J.A. 2009. Estudo de modelos e caracterização do comportamento mecânico da madeira. PhD Thesis, Universidade do Minho, Guimarães, Portugal. Available<http://hdl.handle.net/1822/9696>.

Villegas, M.S.; Rivera, S.M. 2002. Revisión xilológica de las principales especies del género Eucalyptus L'Herit. cultivadas en Argentina. Revista de la Facultad de Agronomía 105(1):9-28. 